\title{
HUBUNGAN FOOD CHOICE TERHADAP KESEHATAN MENTAL PADA REMAJA DI KOTA PAREPARE
}

\author{
Food choice Relationship to Mental Health in Adolescents In The City of Parepare \\ Yayu Adenengsi, Haniarti, Ayu Dwi Putri Rusman \\ (Program Studi Kesehatan Masyarakat Fakultas Ilmu Kesehatan Universitas Muhammadiyah \\ Parepare) \\ (yayuadenengsi@gmail.com)
}

\begin{abstract}
ABSTRAK
Kebiasaan mengkonsumsi makanan sehat telah berubah akibat perkembangan ekonomi yang begitu pesat. Hal ini ditandai dengan akses yang semakin mudah terhadap makanan yang tidak sehat dan juga harga yang lebih murah dibandingkan dengan makanan sehat. Tujuan untuk mengetahui hubungan food choice terhadap kesehatan menal pada remaja di Kota Parepare.Jenis penelitian yang digunakan adalah kuantitatif dengan pendekatan deskriptif. Desain yang digunakan adalah cross sectionalstudy. Populasi yaitu semua pengunjung remaja di lapangan Andi Makkasau Kota Parepare, pengambilan sampel dengan metode teknik non probability sampling sebanyak 99 orang diperoleh dengan menggunakan rumus Slovin. Analisis data dengan menggunakan chi square diterima jika nilai $p<0,05$ dan $\mathrm{H}_{0}$ ditolak jika nilai $p>0,05$. Hasil penelitian diperoleh tidak ada hubungan food choice terhadap kesehatan mental pada remaja dengan nilai $(p=0,676)$. Diharapkan kepada remaja untuk memperhatikan cara pemilihan makanan dan menjaga pola makan agar kesehatan remaja dapat terjaga khususnya pada kesehatan mental .
\end{abstract}

\section{Kata Kunci : Food choice, kesehatan mental, remaja}

\begin{abstract}
The habit of consuming healthy food has changed due to the rapid economic development. This is characterized by easier access to unhealthy food and cheaper prices compared to healthy food. The aim was to determine the relationship between food choice for menal health in adolescents in the city of Parepare.The type of research used is quantitative with a descriptive approach. The design used is a cross sectional study. The population is all teenage visitors in the Andi Makkasau field in Parepare City, taking samples with 99 non-probability sampling techniques was obtained using Slovin formula. Data analysis using chi square is accepted if the value of $p<0.05$ and $H_{-} O$ is rejected if the value of $p>0.05$.The results showed that there was no food choice relationship to mental health in adolescents with a value $(p=0.676)$. It is expected that adolescents will pay attention to how food is chosen and maintain a diet so that adolescent health can be maintained especially on mental health.
\end{abstract}

Keywords: Food choice, mental health, youth 


\section{PENDAHULUAN}

Pemilihan makanan (food choice) adalah skema sederhana dari berbagai faktor yang disaring untuk keputusan akhir. Pemilihan makanan adalah subjek penelitian gizi, ilmu makanan, psikologi, antropologi, sosiologi, dan cabang lain dari ilmu-ilmu alam dan sosial. Hal ini juga dari kepentingan praktis besar bagi industri makanan dan terutama upaya pemasaran (Mega, 2016). ${ }^{1}$

Hasil penelitian Damopolii, Mayulu dan Masi (2013)², mendapatkan hubungan antara konsumsi makanan cepat saji dan kejadian yang berpengaruh dalam pemilihan makanan pada remaja, yakni: gayahidup modern, acara-acara sosial di restoran makanan cepat saji danpemasaran yang gencar terutama melalui media televisi. MahasiswaAkademi Keperawatan Panti Kosala Surakarta tingkat II (sebagai responden) pernah mendapatkan pembelajaran mengenai gizi dan keterkaitannya dengan kesehatan, namun dalam pola konsumsinya juga dipengaruhi oleh perilaku khasmereka sebagai remaja dan lebih menyukai makanan cepat saji yangdianggap lebih praktis/efisien dari segi waktu, biaya, mudah didapat, dan rasa yang bisa menambah selera makan (Santoso \& Velania, 2017) ${ }^{3}$.

Saat ini, kebiasaan konsumsi makanan sehat telah berubah akibat perkembangan ekonomi yang begitu pesat. Hal ini ditandai dengan akses yang semakin mudah terhadap makanan yang tidak sehat dan juga harga yang lebih murah dibandingkan dengan makanan sehat (Rulliyati, 2017) ${ }^{4}$.

Berdasarkan hasil riset kesehatan dasar (Riskesdas 2013) ${ }^{5}$, angka prevalensi gangguan mental emosional yang ditunjukan dengan gejala depresi dan kecemasan adalah sebesar 6 persen untuk usia 15 tahun ke atas atau sekitar 14 juta orang.

Rentang usia remaja menurut WHO merupakan penduduk berusia 1019 tahun, sedangkan menurut Peraturan Menteri Kesehatan RI nomor 25 tahun 2014 remaja ialah penduduk berusia 1018 tahun. Berdasarkan proyeksi penduduk tahun 2015. Jumlah penduduk remaja usia 10-19 tahun di Indonesia adalah sebanyak 44.556.900 yaitu sekitar $17.44 \%$ dari jumlah total penduduk Indonesia.

Remaja merupakan periode kritis perkembangan anak menjadi dewasa, pada saat ini terjadi perkembangan hormonal, fisik, psikologis dan sosial 
yang cepat. Masa peralihan pada usia remaja tidak dapat dikatakan sebagai anak kecil dan juga belum dapat dikatakan sebagai orang dewasa. Remaja ingin mencoba banyak hal baru yang dapat membuktikan dirinya sebagai orang dewasa, tidak jarang hal ini yang membuatnya mencoba berbagai hal yang berisiko antara lain konsumsi alkohol, narkoba, memiliki pacar, perilaku seksual, memiliki peer group, dan berbeda pendapat dengan orangtua. Berbagai perubahan yang terjadi pada diri dan perilaku berisiko remaja ini seringkali memicu konflik antara remaja dengan dirinya sendiri (konflik internal), dan konflik dengan lingkungan sekitarnya (konflik eksternal). Apabila konflik ini tidak diselesaikan dengan baik maka akan memberikan dampak negatif terhadap perkembangan remaja tersebut di masa mendatang, terutama terhadap pematangan karakternya dan tidak jarang memicu terjadinya gangguan mental. Masa remaja awal adalah masa perubahan psikologis, dimana remaja akan diuji kemampuannya dalam melaksanakan peran dan mengembangkan keterampilan. Ketidakstabilan emosi juga menyebabkan orang lain sulit memahami remaja dan kadangkala remaja pun sering tidak mengerti dirinya sendiri (Mubasyiroh, Putri, \& Tjandrarini, 2015) ${ }^{6}$.

Pada remaja usia 10-19 tahun di Indonesia merupakan hampir seperlima dari total penduduk. Di masa mendatang, mereka menjadi penggerak utama ekonomi dan perubahan sosial sehingga perlu menjadi fokus perhatian dan titik intervensi yang strategis bagi pembangunan sumber daya manusia di masa depan (Mubasyiroh, Putri, \& Tjandrarini, 2015) ${ }^{6}$.

Hasil penelitian yang dilakukan oleh Deva Riva'a Fassah dapat dijelaskan dari sudut pandang fisiologis. Perilaku makan diatur oleh $P F C$ (Prefrontal Cortex) yang berfungsi mengenal rasa lapar dan kenyang. $P F C$ (Prefrontal Cortex) dapat dengan mudah didominasi oleh emosi karena terletak di bagian limbik yang merupakan pusat kontrol emosi (Seawards, 2012). Dalam Handbook of Food and Addiction, Epel, et al., (2010) menjelaskan bahwa bagian dari sistem limbik, yaitu amigdala dan hipotalamus, berfungsi mengatur sinyalsinyal penting untuk kelangsungan hidup individu sehingga ketika stres datang, PFC (Prefrontal Cortex) dapat menyalahartikan keadaan emosional sebagai rasa lapar. Oleh sebab itu, emotional distress yang berkepanjangan dapat membentuk perilaku makan yang buruk dan mengarah pada gangguan 
makan,seperti overeating yang berujung pada obesitas (Deva R, 2014) ${ }^{7}$.

Mengkonsumsi makanan cepat saji secara rutin tak hanya mengakibatkan obesitas, tetapi juga berdampak signifikan pada mental.Dilansir dari Reader Digest, sebuah studi menunjukkan pengaruh konsumsi makanan cepat saji pada psikologis. Selain depresi, mengonsumsi makanan cepat saji secara berlebihan dapat meningkatkan risiko kecemasan. Karbohidrat olahan pada makanan cepat saji dapat menyebabkan gula darah turun.Gula darah yang sangat rendah dapat menyebabkan serangan panik, insomnia, dan gejala kecemasan. Selain itu, kekurangan asam lemak omega-3 dalam makanan yang digoreng bisa menyebabkan otak mengalami gejala kecemasan. Berdasarkan uraian latar belakang tersebut peneliti tertarik melakukan penelitian yang berjudul hubungan food choice terhadap kesehatan mental pada remaja di Kota Parepare.

\section{BAHAN DAN METODE}

Jenis penelitian yang digunakan adalah kuantitatif dengan pendekatan deskriptif. Desain penelitian yang digunakan adalah cross sectional study yang bertujuan untuk mencari hubungan food choice terhadap kesehatan mental pada remaja di kota Parepare.Lokasi pada penelitian ini di kota Parepare. Waktu pelaksanaan penelitian ini adalah 2 bulan, yaitu pada bulan Mei sampai Juli 2018.Data yang digunakan dalam penelitian ini adalah data primer dan data sekunder. Pengumpulan data primer dalam penelitian ini diperoleh dari hasil wawancara dengan menggunakan kuesioner. Pengumpulan data sekunder dilakukan dengan cara pengambilan data jumlah pengunjung Lapangan Andi Makkasau Kota Parepare.Adapun instrumen penelitian yang digunakan dalam penelitian ini adalah menggunakan lembar kuesioner di mana kuesioner tersebut di bagikan langsung pada pengunjung remaja lapangan Andi Makkasau Kota Parepare.

Populasi berjumlah 167 remaja. Pengolahan data adalah pengubahan data mentah menjadi data masak sampai pada penggunaan data statistik deskriptif sehingga mudah ditafsirkan.Pengolahan data dilakukan dengan menggunakan komputer dengan menggunakan program SPSS (Statistical Product and Service Solutions) versi 24.Adapun langkahlangkah pengolahan data yang digunakan adalah sebagai berikut : Editing, Coding, Data Entry, Cleaning.

\section{HASIL}


Tabel 1 menunjukkan bahwa kategori umur 14-16 tahun sebanyak 61 $(61,6 \%)$ responden, sedangkan kategori umur 17-19 tahun sebanyak 38 (38,4\%). Untuk kategori jenis kelamin perempuan lebih besar yaitu $92 \quad(92,9 \%)$ dibandingkan dengan laki-laki yaitu sebanyak 7 (7,1\%). Untuk kategori besar uang saku kategori Rp. 5.000 - Rp. 10.000 sebanyak $34(34,3 \%)$ dan untuk kategori Rp. 10.000 - Rp. 15.000 sebanyak $38(38,4 \%)$ sedangkan kategori >Rp. 15.000 sebanyak 27 (27,3\%).

Tabel 2 menunjukkan bahwa pemilihan makanan yang sehat lebih banyak dengan jumlah responden sebanyak $96 \quad(97,0)$ responden dibandingkan dengan yang tidak sehat sebanyak $3(3,0)$ responden. Tabel 3 menunjukkan bahwa kesehatan mental yang sehat lebih banyak yaitu sebanyak $87(87,9 \%)$ responden dibandingkan dengan yang sakit sebanyak $12(12,1 \%)$ responden.

Tabel 4 menunjukkan bahwa pemilihan makanan dengan kategori sehat lebih banyak pada kesehatan mental dengan kategori sehat sebanyak 84 responden $(96,6 \%)$ dibandingkan dengan pemilihan makanan yang tidak sehat ddengan kesehatan mental kategori sakit sebanyak 0 responden $(0,00 \%)$ berdasarkan analisis Chi Square diperoleh nilai $p=0,676>\alpha(0,05)$ yang menunjukkan bahwa tidak ada hubuungan pemilihan makanan (Food Choice) terhadap kesehatan mental pada remaja.

\section{PEMBAHASAN}

Hasil penelitian ini menunjukan bahwa responden lebih banyak memilih makanan sehat yaitu sebanyak 96 orang $(97,0)$ dibanding makanan yang tidak sehat. Hasil tersebut menunjukkan bahwa pemilihan makanan remaja telah mampu memilih makanan yang sehat dibanding dengan yang tidak sehat. Hal ini dikarenakan remaja jaman sekarang telah mudah mendapatkan informasi tentang makanan sehat, sehingga dapat menjaga kesehatannya masing-masing.

Secara umum, banyak faktor yang mempengaruhi perilaku remaja lebih memilih mengkonsumsi makanan cepat saji antara lain karena meniru orang lain, pergaulan, ajakan teman dan kesenangan. Selain itu terdapat juga faktor lain yaitu adanya promosi media seperti iklan yang mempromosikan fast food. Iklan dapat mempengaruhi pembelian makanan cepat saji bagi remaja.Semakin banyak iklan yang dilihat oleh remaja dapat mempengaruhi peningkatan pembelian makanan cepat saji.Perilaku remaja tersebut didukung oleh sikap yang merespon keinginan mereka untuk mencoba dan 
mengkonsumsi makanan cepat saji (Triyanti, 2014) $^{8}$.

Otak kita membutuhkan nutrisi agar tetap sehat dan berfungsi dengan baik, seperti organ yang ada di dalam tubuh kita. Melakukan diet yang seimbang dapat membantu kesehatan mental kita karena dapat membantu cara berpikir dan cara kita merasakan sesuatu. Cobalah untuk mengkonsumsi 5 porsi buah-buahan dan sayuran setiap hari serta minum air putih. Minimalisir konsumsi minuman berkafein, berkadar gula tinggi, dan alkohol. Hindari makan, minum alkohol, merokok, dan menggunakan obat-obat terlarang untuk menyelesaikan masalah atau mengatasi perasaan tidak menyenangkan yang kita alami. Hal seperti itu tidak akan menyelesaikan masalah, justru sebaliknya akan menciptakan masalah baru.

Hasil penelitian mendukung penelitianyang dilakukan oleh Februhartanty danIswarawanti (2016) ${ }^{9}$ yang menyatakan bahwarata-rata jumlah uang jajan yang diterimaanak selama berada disekolah berkisar antara Rp2000 sampai dengan Rp7000. Perbedaanjumlah uang jajan yang diterima tidakmembuat anak terampil dalam menentukanjajanan sehat. Hasil penelitian menunjukkan bahwa tidak ada perbedaan yang signifikan jumlah uang jajan anak yang diberikan oleh orangtua selama disekolah terhadap keterampilan anak dalam memilih jajanan sehat. Lebih lanjut ia menambahkan anak yang memperoleh uang jajan lebih banyak berpeluang untuk terkontaminasi oleh jajanan tidak sehat.

Konsep hidup sehat ala Ayurveda serta mengenali karakter tubuh, maka kali ini saya akan menulis tentang hubungan makanan dengan keseimbangan tubuh dan faktor kejiwaan. Makanan mempunyai fungsi yang sangat penting dalam menyelaraskan pikiran dan emosi kita. Makanan sangat mempengaruhi keadaan mental kita. Contohnya, untuk sebagian orang begitu minum alkohol seteguk atau minum kopi setengah cangkir maka mereka langsung gemetar, pikiran sulit diajak kompromi, dan tidak bisa mengambil keputusan dengan baik. Bahkan mengendarai mobil pun tidak berani. Ada lagi yang setelah makan makanan yang pedas, menjadi lemas dan mengantuk. Nah coba bayangkan kalau dia seorang operator alat berat atau seorang guru yang harus menerangkan pelajaran penting di depan kelas Belum lagi ada anak-anak yang begitu minum minuman bersoda yang kaya gula dan zat tambahan lainnya menjadi hiperaktif dan tidak bisa konsentrasi di dalam kelas, bahkan mereka cenderung mengganggu 
teman atau malahan memalak temantemannya.

Hasil penelitian ini menunjukkan kesehatan mental pada remaja lebih banyak kategori sehat yaitu 87 responden $(87,9 \%)$ dibanding dengan yang sakit yaitu 12 responden $(12,1 \%)$. Hal tersebut menunjukkan bahwa kesehatan mental pada remaja masih sehat karena mereka masih sering berinteraksi dengan keluarga, teman sebaya maupun masyarakat luas. Sehingga mereka dapat mengatasi masalah stress khususnya pada remaja yang usia 10-19 tahun.

Kesehatan mental adalah kondisi seseorang yang berkaitan dengan penyesuaian diri yang aktif dalam menghadapi dan mengatasi masalah dengan mempertahankan stabilitas diri, juga ketika berhadapan dengan kondisi baru, serta memiliki penilaian nyata baik tentang kehidupan maupun keadaan diri sendiri. Definisi dari Jahoda mengandung istilah-istilah yang pengertiannya perlu dipahami secara jelas yaitu penyesuaian diri yang aktif, stabilitas diri, penilaian nyata tentang kehidupan dan keadaan diri sendiri ( Dokter Sehat, 2014) ${ }^{10}$.

Masa remaja merupakan masa yang penuh gejolak, pada masa ini mood (suasana hati) bisa berubah dengan sangat cepat. Perubahan mood (swing) yang drastis pada para remaja ini seringkali dikarenakan beban pekerjaan rumah, pekerjaan sekolah, atau kegiatan sehari-hari di rumah. Meski mood remaja yang mudah berubah-ubah dengan cepat, hal tersebut belum tentu merupakan gejala atau masalah psikologis (Ikatan Dokter Anak Indonesi, 2013) ${ }^{11}$.

Kesehatan mental merupakan hal penting yang harus diperhatikan selayaknya kesehatan fisik. Diketahui bahwa kondisi kestabilan kesehatan mental dan fisik saling mempengaruhi. Gangguan kesehatan mental bukanlah sebuah keluhan yang hanya diperoleh dari garis keturunan. Tuntutan hidup yang berdampak pada stres berlebih akan berdampak pada gangguan kesehatan mental yang lebih buruk (Atika Khairun, $2018)^{12}$.

Berbagai penelitian memberikan hasil bahwa adanya hubungan antara kesehatan fisik dan mental seseorang, di mana pada individu yang menderita sakit secara fisik menunjukkan adanya masalah psikis hingga gangguan mental. Sebaliknya, individu dengan gangguan mental juga menunjukkan adanya gangguan fungsi fisiknya. Sehat dan sakit merupakan kondisi biopsikososial yang menyatu dalam kehidupan manusia. Pengenalan konsep sehat dan sakit, baik secara fisik maupun psikis merupakan bagian dari pengenalan manusia terhadap 
kondisi dirinya dan bagaimana penyesuaiannya dengan lingkungan sekitar (Atika Khairun, 2018) ${ }^{13}$.

Nutrisi makanan sangat penting untuk struktur dan fungsi otak, sehingga memiliki dampak yang berpotensi besar pada kesehatan mental. Semakin tubuh penelitian yang kuat poin dengan efek merugikan dari diet yang tidak sehat dan kekurangan gizi, dan untuk nilai pelindung dari diet sehat - bersama dengan suplemen gizi pilih seperti yang diperlukan - untuk menjaga dan meningkatkan kesehatan mental (Sarris, 2018) $)^{14}$.

Hasil penelitian ini tidak sejalan dengan hasil penelitian yang dilakukan oleh Vivi (2014) ${ }^{15}$ analisis korelasi yang dilakukan diperoleh hasil korelasi sebesar 0,615 dengan interprestasi korelasi yang kuat antara pengetahuan dengan perilaku konsumsi. Sedangkan berdasarkan uji keberartian korelasi diperoleh harga $t$ hitung $>\mathrm{t}$ tabel $(41,884$ $>1,667)$ yang berarti bahwa Ha yang berbunyi terdapat hubungan yang positif dan signifikan antara pengetahuan mengenai makanan cepat saji (fast food) dengan perilaku konsumsi fast food pada siswa SMA. Dengan demikian hubungan antara pengetahuan dengan perilaku konsumsi makanan cepat saji (fast food) pada siswa SMA benar-benar berhubungan secara nyata dan berlaku untuk seluruh populasi penelitian.

Para ahli berpendapat telah banyak studi yang dipublikasikan pada tingkat dunia, mengenai hubungan antara kualitas diet dan gangguan jiwa umum (depresi dan gangguan kecemasan), baik pada dewasa maupun anak-anak. "Sudah banyak bukti yang menunjukkan bahwa pola makan yang baik penting bagi kesehatan mental dan raga," (Noviarni, 2015) ${ }^{16}$.

Diet sehat dapat bersifat protektif, sedangkan diet tidak sehat bisa berisiko depresi serta gangguan kecemasan. Ditemukan juga kemungkinan alergi makanan dapat berefek pada schizophreniadan gangguan bipolar. Namun, kebanyakan peneliti lebih memfokuskan diri pada kebiasaan makan dan kesehatan jiwa dalam hubungannya dengan depresi dan gangguan kecemasan (Noviarni, 2015) ${ }^{16}$.

Konsumsi Makanan Cepat Saji Pola konsumsi terkait dengan perilaku khas remaja yang waktu makannya sering masih tidak teratur dan lebih menyukai makan makanan cepat saji di luar rumah bersama teman-temannya (Makki dan Hamdan, 2016) ${ }^{17}$. Selain itu, keputusan dalam pemilihan pola makan/konsumsi pada remaja juga dipengaruhi faktor internal (fisiologis, psikologis dan tipe kepribadian) dan 
faktor eksternal seperti pendidikan kesehatan dan media/periklanan atau informasi yang diperoleh (Barasi, 2007; Seubsman, et al., 2009) ${ }^{18}$. Dalam penelitian ini didapatkan tidak adanya hubungan yang bermakna antara tingkat pengetahuan responden dengan pola konsumsi makanan cepat saji ( $\mathrm{p}=$ 0.441). Hasil tersebut sesuai dengan penelitian Makki dan Hamdan (2016) ${ }^{17}$, yang mendapatkan bahwa pengetahuan tentang makanan cepat saji tidak berpengaruh pada frekuensi kunjungan responden ke restoran makanan cepat saji. Begitu pula dengan penelitain Widyantara $(2013)^{19}$, yang mendapatkan pengetahuan gizi yang baik (55.3\%).

Hal yang sama juga ditunjukkan oleh bagian kesehatan Universitas Harvard di mana jurnal kesehatan yang dimiliki Harvard menunjukkan bagaimana sebuah makanan bisa menentukan cara kerja otak (Kumparan Style, 2017) ${ }^{20}$.

Jika seseorang mengonsumsi makanan yang berkualitas maka otak juga akan berfungsi dengan optimal. Hal ini bisa diibaratkan seperti sebuah mobil yang diisi dengan jenis bensin terbaik maka mesin mobil pun akan berfungsi dengan baik karena tubuh kita layak untuk mendapatkan makanan terbaik (Kumparan Style, 2017) ${ }^{20}$.
Mengkonsumsi

makanan berkualitas tinggi yang dikemas dengan vitamin, mineral dan antioksidan akan membantu dan melindungi otak dari stres oksidatif, yang mana bisa membahayakan sel tubuh (Kumparan Style, 2017) ${ }^{20}$.

Belum banyak orang yang tahu tentang hubungan antara makanan dan suasana hati. Padahal dengan memahami hal ini, maka kita pun akan lebih peduli dengan makanan yang kita santap. Makanan sehat tidak hanya membuat bentuk tubuh menjadi ideal atau proporsional, namun makanan juga terkait dengan aktivitas mental yang lebih sehat (Kumparan Style, 2017) ${ }^{20}$.

Di dalam tubuh, terdapat neurotransmitter yaitu pembawa sinyal ke sel-sel otak atau neutron. Dan salah satu neutrotransmitter yang telah diidentifikasi selama bertahun-tahun adalah 'hormon kebahagiaan' atau sering disebut dengan serotonin (Kumparan Style, 2017) $)^{20}$.

\section{KESIMPULAN DAN SARAN}

Berdasarkan hasil penelitian yang dilakukan di Kota Parepare pada tanggal 17 Mei sampai 27 Juli 2018 dapat disimpulkan tidak ada hubungan food choice terhadap kesehatan mental pada remaja di Kota Parepare $(p=0,676)$. Berdasarkan kesimpulan tersebut maka 
saran yang dapat disampaikan peneliti diharapkan kepada remaja untuk memperhatikan cara pemilihan makanan dan menjaga pola makan agar kesehatan remaja dapat terjaga khususnya pada kesehatan mental.

\section{DAFTAR PUSTAKA}

1. Mega. Faktor-faktor yang Mempengaruhi Komsumsi dan Frekuensi Makanan Jajanan Siswa Kelas X Tata Boga SMK N 1 Sewon. [Skripsi]. Universitas Negeri Yogyakarta; 2016.

2. Damopoli, Mayulu dan Masi. Hubungan Tingkat Pengetahuan Tentang Makanan Cepat Saji dengan Pola Komsumsinya pada Mahasiswa Tingkat II Akper Panti Kosala Surakarta. [Jurnal KOSALA]. 2017; 5: 31-36.

3. Santoso dan Velania. Kenakalan Remaja dan Penanganannya. [Jurnal Penelitian dan PPM]. 2017. 4: 129389.

4. Rulliyati. Benarkah Makanan Bisa Memengaruhi Mood Seseorang; $2017 . \quad$ [online] https://kumparan.com/@kumparanst yle/benarkah-makanan-bisamempengaruhi-mood-seseorang [Diakses pada tanggal 3 September 2018].

5. [RISKESDAS] Riset Kesehatan Dasar. Badan Penelitian Dan Pengembangan Kesehatan Kementerian Kesehatan RI; 2013: Hal 11.

6. Mubasyiroh, Putri dan Tjandrarini. Diet Sehat Pengaruhi Kesehatan
Metal; 2015. [online] https://lifestyle.sindonews.com/read/ 1039647/152/diet-sehat-pengaruhi-

kesehatan-mental-1441158378

[Diakses pada tanggal 14 agustus 2018].

7. Deva RF. dkk. Hubungan Antara Emotional Distress dengan Perilaku Makan Tidak Sehat Pada Mahasiswa Baru [jurnal]. 2014: Vol.10 No.1.

8. Triyanti V. Hubungan Pengetahuan Mengenai Makanan Cepat Saji (Fast Food) Dengan Perilaku Konsumsi Makanan Cepat Saji (Food Choice) Pada Siswa Sekolah Menengah Atas Pembangunan Laboratorium Universitas Negeri Padang. [Skripsi]. Universitas Negeri Padang; 2014.

9. Februhartanty dan Iswarawanti. Hubungan Besaran Uang Saku dengan Pemilihan Jajanan Sehat. [Jurnal Kesehatan Al-Irsyad (JKA); 2016: Vol 9. No.1.

10. Dokter Sehat. Menjaga Kesehatan Mental. 2014. [online] https://doktersehat.com/menjagakesehatan-mental/ [Diakses pada tanggal 14 agustus 2018].

11. [IDAI] Ikatan Dokter Anak Indonesia. Masalah Kesehatan Mental Emosional Remaja. 2013. [online]

http://www.idai.or.id/artikel/seputarkesehatan-anak/masalah-kesehatanmental-emosional-remaja (Diakses pada tanggal 7 Agustus 2018.

12. AtikaKhairun. Kesehatan Mental Penting Untung Semua Orang. 2018. [online] https://student.cnnindonesia.com/ed ukasi/20180119115128-445270131/kesehatan-mental-penting- 
untuk-semua-orang/ [Diakses pada tanggal 3 September 2018].

13. Sarris J. Tujuh Nutrisi Penting Untuk kesehatan Mental Dan Tempat Menemukannya. 2018. [online]https://id.innerself.com/cont ent/living/health/foodandnutrition/10806-seven-nutrientsimportant-for-mental-healthandwhere-to-findthem.html [Diakses pada tanggal 3 September 2018].

14. Vivi. Pengaruh Pola Makan Fast Food terhadap Status Gizi Remaja di SMA NEGERI 1 Enrekang Kabupaten Enrekang. [Skripsi]. Universitas Muhammadiyah Parepare; 2014.

15. Noviarni. Kesehatan Mental Masyarakat Indonesia (Pengetahuan, dan Keterbukaan Masyarakat Terhadap Gangguan Kesehatan Mental). [Jurnal Prodising KS: RISET \& PKM]. 2014. 2 : 147-300.
16. Makki dan Hamdan. Hubungan Aktivitas Fisik dan Kebiasaan Komsumsi Fast Food dengan Status Gizi Lebih Remaja SMA Labschool Kebayoran Baru Jakarta Selatan. [Skripsi]. Universitas Muhammadiyah Jakarta; 2016.

17. Barasi. Faktor-faktor yang Mempengaruhi Pemilihan Makanan pada Remaja di Surabaya. [Skripsi]. Universitas Kristen Petra; 2007.

18. Widyantara. Hubungan Kesehatan Mental dan Food Choice terhadap Kejadian Hipertensi pada Guru Sekolah Menengah di Kota Makassar. [Skripsi]. Universitas Hasanuddin Makassar; 2013.

19. Kumparan Style. Pengertian Remaja Menurut WHO. 2017. [online] http://definisipakar.blogspot.co.id/20 17/09/pengertian-remaja-menurutwho.html [Diakses pada tanggal 8 Mei 2018].

\section{Lampiran}


Tabel 1. Disribusi Karakteristik Responden Berdasarkan Umur, Kelamin, Besar Uang Saku

\begin{tabular}{|c|c|c|}
\hline Karakteristik & $\mathbf{n}$ & $\%$ \\
\hline \multicolumn{3}{|l|}{ Umur (Tahun) } \\
\hline $14-16$ & 61 & 61,6 \\
\hline $17-19$ & 38 & 38,4 \\
\hline Total & 99 & 100,0 \\
\hline \multicolumn{3}{|l|}{ Jenis kelamin } \\
\hline Laki-laki & 7 & 7,1 \\
\hline Perempuan & 92 & 92,9 \\
\hline Total & 99 & 100,0 \\
\hline \multicolumn{3}{|l|}{ Besar uang saku } \\
\hline Rp. 5.000 - Rp. 10.000 & 34 & 34,3 \\
\hline Rp. 10.000 - Rp. 15.000 & 38 & 38,4 \\
\hline$>$ Rp. 15.000 & 27 & 27,3 \\
\hline Total & 99 & $\mathbf{1 0 0 , 0}$ \\
\hline
\end{tabular}

Tabel 2. Distribusi Karateristik Responden Berdasarkan Pemilihan Makanan (food choice)

\begin{tabular}{lrc}
\hline Pemilihan makanan & $\mathrm{N}$ & $\%$ \\
\hline Tidak Sehat & 3 & 3,0 \\
Sehat & 96 & 97,0 \\
\hline Total & 99 & 100,0 \\
\hline
\end{tabular}

Tabe1 3. Distribusi Karakteristik Responden Berdasarkan Kesehatan Mental

\begin{tabular}{llc}
\hline Kesehatan Mental & $\mathrm{N}$ & $\%$ \\
\hline Sakit & 12 & 12,1 \\
Sehat & 87 & 87,9 \\
\hline Total & 99 & 100,0 \\
\hline
\end{tabular}

4. Hubungan Pemilihan Makanan Dengan Kesehatan Mental Pada Remaja di Kota Parepare

\begin{tabular}{|c|c|c|c|c|c|c|c|}
\hline \multirow{3}{*}{$\begin{array}{l}\text { Variabel } \\
\text { Pemilihan }\end{array}$} & \multicolumn{4}{|c|}{ Kesehatan Mental } & \multirow{2}{*}{\multicolumn{2}{|c|}{ Total }} & \multirow[t]{4}{*}{$P$} \\
\hline & \multicolumn{2}{|c|}{ Tidak sehat } & \multicolumn{2}{|c|}{ Sehat } & & & \\
\hline & $\mathrm{n}$ & $\%$ & $\mathrm{n}$ & $\%$ & $\mathrm{n}$ & $\%$ & \\
\hline \multicolumn{7}{|l|}{ Makanan } & \\
\hline Sakit & 0 & 0,0 & 12 & 100,0 & 12 & 100,0 & \multirow{3}{*}{0,676} \\
\hline Sehat & 3 & 3,4 & 84 & 96,6 & 87 & 100,0 & \\
\hline Total & 3 & 3,0 & 96 & 97,0 & 99 & 100,0 & \\
\hline
\end{tabular}


